\title{
Extinction of the effect of one ECS
}

HENRY E. ADAMS

UNIVERSITY OF GEORGIA

To determine if the effects of one ECS were temporary or permanent 40 rats were given two initial learning sessions in a hurdle box. One group received ECS and another group received sham ECS. The two groups were then divided into a group which was placed in the hurdle box compartment (where ECS or sham ECS was administered) 5 min. per day for three days (extinction group) while the remaining group stayed in home cages. The results indicate that ECS without extinction procedures causes a decrement in relearning. With extinction procedures ECS caused no decrement in learning. These results suggest that the effects of a single ECS are temporary since they can be extinguished.

Several conflicting interpretations have been suggested to explain the effects of electroconvulsive shock (ECS). As a result, there has been some controversy regarding the adequacy of interference explanations (Adams \& Lewis, 1962a, 1962b; Coons \& Miller, 1960; Lewis \& Adams, 1963; Lewis \& Maher, 1965) as opposed to a consolidation hypothesis (Leonard \& Zavala, 1964; Madsen \& McGaugh, 1961). These two approaches differ primarily in that the consolidation hypothesis suggests that the decrement in retention is permanent (i.e., the dis ruption of an engram) while interference or competing response hypotheses indicate that this effect is temporary. Hudspeth \& Gerbrandt (1965) have attempted to resolve these conflicting viewpoints by presenting a unifying hypothesis. They indicated that with repeated ECS trials the data tend to support an interference explanation while with single ECS treatment the data are consistent with the consolidation hypothesis. This explanation has also been suggested by Leonard \& Zavala (1964) as well as McGaugh \& Madsen (1964).

Adams \& Lewis (1962b) have demonstrated that effects of repeated ECS treatments can be extinguished. However, they did not have a control for the extinction procedure. The present study includes a control group for the extinction procedure and will attempt to determine if the effects of a single ECS treatment is temporary or permanent by trying to extinguish the decremental effect of ECS.

\section{Method}

Subjects. Forty male, albino rats were randomly assigned to the four conditions of the experiment. They weighed between 200 and $250 \mathrm{gm}$ at the beginning of the experiment and were maintained on an ad lib schedule throughout the experiment.

Apparatus. The apparatus was a modified MillerMowrer hurdle box which is described in detail in a previous report (Adams \& Lewis, 1962a). The two compartments were separated by a $2-1 / 2$ in. high hurdle and by a manually operated guillotine door. One compart- ment was painted black and contained a grid floor through which an electric shock could be administered. Raising the guillotine door resulted in an intermittent activation of a small bulb (CS) located on the end wall of the black compartment. Ten sec. after the onset of the flickering light, a current of .8 ma charged the grid floor and the CS was terminated. Responses were timed in .01 sec. from the onset of the light to the lowering of the guillotine door immediately after $S$ jumped over the hurdle and entered the white compartment.

The ECS was a current of approximately $45 \mathrm{ma}$ administered for $.3 \mathrm{sec}$. through alligator clips attached to S's ears.

Procedure. All Ss were given three original learning trials a day for two days. They were then divided into four groups, using a factorial design. Approximately five min. after the last trial on the second day, onehalf of the Ss were given ECS in the black compartment while the remaining Ss were not given ECS. Only one ECS was given. For the next three days one-half of each group was placed in the black compartment box for 5 min. of extinction per day while the other Ss remained in their living cages. On the sixth day all Ss were given 30 relearning trials.

Results

An analysis of variance of the avoidance responses indicates that there was no significant difference between Ss who received ECS and Ss who did not receive ECS $(F=2.82$, $d f=1 / 36)$. Ss receiving extinction trials performed significantly better than Ss who did not receive extinction trials $(F=10.56, \mathrm{df}=1 / 36)$. The trial blocks variable was also significant ( $F=23.29, d f=5 / 180$ ). The higher order interactions of ECSby Extinction $(F=7.04$, $\mathrm{df}=1 / 36$ ) and ECS by Extinction by Trial Block ( $F=$ 3.54, $d f=5 / 180$ ) were also significant. As may be seen in Fig. 1, ECS interfered with relearning when no extinction procedure was used. However, when Ss were given ECS with extinction procedures, they relearned at the same rate as Ss who had not received ECS. When Ss were not given ECS, extinction or no extinction procedures did not differentially influence their performance.

\section{Discussion}

The present results indicate that the effects of one ECS are temporary and can be extinguished. These results cast doubt on the interpretation of ECS, which indicates that it disrupts the consolidation of an engram. It is possible that the crucial factor in explaining the conflicting results of ECS is passive versus active avoidance procedures rather than single versus repeated ECS treatment. This interpretation has also been suggested by Hudspeth \& Gerbrandt (1965) and would 


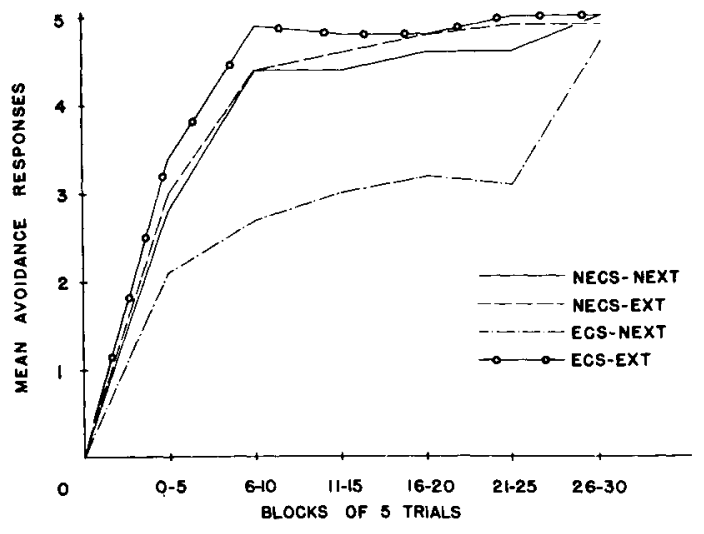

Fig. 1. Mean number of avoidance responses during retraining. $($ NECS $=$ no ECS, ECS $=$ ECS, EXT $=$ extinction, NEXT $=$ no extinction).

explain the present results which support an interference hypothesis since an active avoidance procedure was utilized. Chorover \& Schiller (1965) have presented data which they interpret to indicate that the consolidated process is complete within $10 \mathrm{sec}$. If they are correct, then this study is not relevant to the consolidation hypothesis.

There is little doubt that the effects of a single ECS are difficult to handle within a conditioned fear, immobility, or inhibition framework since this would require one trial learning. However, a competing response hypothesis does not necessarily have to maintain that the organism must learn to perform some other response. The effect of a single ECS may be due to the introduction of a novel noxious stimulus which causes a disinhibition of responses which were previously inhibited during the process of learning. Exposing the $S$ to the cues associated with the learning and ECS may habituate the $\mathrm{S}$ to the disinhibiting effect resulting in no decrement in performance. Further research with the single ECS method should attempt to differentiate between this effect, which is temporary and probably eliminated with repeated trials, and the disruption of an engram. With repeated ECS treatments, it is crucial to attempt to determine which of the several interference hypotheses (i.e., conditioned inhibition, conditioned fear, or conditioned immobility) is correct.

\section{References}

Adams, H. E., \& Lewis, D. J. Electroconvulsive shock, retrograde amnesia, and competing responses. J. comp. physiol. Psychol., 1962a, 55, 299-301.

Adams, H. E., \& Lewis, D. J. Retrograde amnesia and competing responses. J. comp. physiol. Psychol., 1962b, 55, 302-305.

Chorover, S. L., \& Schiller, P. H. Short term retrograde amnesia (RA) in rats. J. comp, physiol. Psychol., 1965, 59, 73-78.

Coons, E. E., \& Miller, N. E. Conflict versus consolidation of memory traces to explain "retrograde amnesia" produced by ECS. J. comp. physiol. Psychol., 1960, 53, 524-531.

Hudspeth, J. J., \& Gerbrandt, L. K. Electroconvulsive shock: Conflict, competition, consolidation, and neuroanatomical functions. Psychol. Bull., 1965,63, 377-383.

Leonard, D. J., \& Zavala, A. Electroconvulsive shock: Retroactive amnesia and the single shock method. Science, 1964, 146, 10731079.

Lewis, D. J., \& Maher, B. H. Neural consolidation and electroconvulsive shock. Psychol. Rev., 1965, 72, 225-239.

McGaugh, J. L., \& Madsen, M. C. Amnesic and punishing effects of electroconvulsive shock. Science, $1964,144,182-183$.

Madsen, M. C., \& McGaugh, J. L. The effect of ECS on one-trial avoidance learning. $J$. comp. physiol. Psychol., 1961, 54, 522523.

Note

1. This research was supported by a Public Health Service research grant, MH-10039-01, from the National Institute of Mental Health, Public Health Service. 